\title{
Frequency of the mitochondrial A1555G mutation in Iranian patients with non- syndromic hearing impairment
}

\author{
M. Montazer Zohour ${ }^{1}$, M.T. Akbari ${ }^{* *}$ and M. Hashemzadeh Chaleshtori ${ }^{2}$ \\ ${ }^{1}$ Department of Medical Genetics, Faculty of Medical Sciences, Tarbiat Modares University, Tehran-14115-111, Iran. \\ ${ }^{2}$ Cellular and Molecular Research Center, Shahrekord University of Medical Sciences. Shahrekord, Iran. \\ mtakbari@modares.ac.ir
}

\begin{abstract}
Mitochondrial 12S rRNA gene mutations account for non-syndromic hearing impairment (NSHI). The A1555G substitution is the most common mitochondrial DNA mutation and is associated with both aminoglycoside-induced HI and NSHI. Its frequency is variable among populations of different ethnic background. The purpose of the present survey was to determine the frequency of the A1555G mutation in the Iranian probands with NSHI. We have screened 152 unrelated Iranian probands with NSHI with childhood onset and 548 normal hearing controls for the occurrence of the A1555G mutation using PCR-RFLP method. Totally, 2 patients carrying the homoplasmic A1555G mutation were identified with a total frequency of $1.3 \%$ in Iran. Mutation A1555G had a variable frequency among subpopulations of different ethnic origins in Iran: Azeri Turkish (4.16\%), Lure (0.0\%), Fars (0.0\%) and Bushehri $(2.86 \%)$. The A1555G mutation was not found in any member of the controls. Our study shows that the frequency of the A1555G mutation in Azeri Turkish and Bushehri hearing impaired patients is compatible with that reported for Caucasian populations.
\end{abstract}

Keywords: A1555G, Non-syndromic hearing impairment, Iran, mtDNA.

\section{Introduction}

Hearing impairment (HI) is the most heterogeneous human disorder known that occurs 1-3 in 1000 newborns (Morton \& Nance, 2006). Approximately $70 \%$ of neonates affected by hereditary HI are non-syndromic (NSHI). Mutations in both nuclear and mitochondrial genes can lead to NSHI. According to the Hereditary Hearing Loss homepage (http://hereditaryhearingloss.org/) more than 125 loci and approximately 64 genes for NSHI have been identified in human. Until now, 7 genes have been discovered in mitochondrial DNA, mutations of which represent 1\% of pre-lingual NSHI cases (Marazita et al., 1993). In Caucasian population, it has been shown that at least $5 \%$ of post-lingual NSHI cases are caused by pathogenic mtDNA mutations (Jacobs et al., 2005). Mutations in the mitochondrial genome may be found in around $20 \%$ of hereditary post-lingual $\mathrm{HI}$ but this might be variable as a consequence of ethnic differences (Estivill et al., 1998). A majority of mitochondrial HI have been associated predominantly with mutations in the MT-RNR1 (12S rRNA) and the MT-TS1 (tRNA ${ }^{\text {ser }(\mathrm{UCN})}$ ) genes. The A1555G mutation in MT-RNR1 is the most prevalent mutation of mitochondrial genome, associated with both late onset and congenital NSHI. The A1555G mutation has been identified in more than 120 families throughout the world with different frequencies among different population groups. This mutation mostly occurs in homoplasmy but heteroplasmic status can also be found. Phenotypic manifestation of the A1555G mutation is extremely variable ranging from severe congenital NSHI to completely normal hearing phenotype (Li et al., 2004b), deaf individuals harboring the A1555G mutation show a variable age of onset and severity; while some subjects are congenitally hearing impaired, some others have adult onset HI, still others may show slowly progressive NSHI. Such variable expressivity may suggest the presence of major modulators including modifier genes, mitochondrial haplotypes and aminoglycoside antibiotics. We launched the present study to screen the mitochondrial mutation A1555G for the first time in Iranian probands associated with childhood onset NSHI.

\section{Methods}

\subsection{Subjects}

In this study, 152 unrelated families with 2 or more NSHI subjects were recruited from 5 provinces with four different languages and ethnic backgrounds from Iran including Charmahal va Bakhtiari and Kohgiluyeh va Boirahmad provinces (Lure) in the southwest (50 cases), Fars province (Fars) in the south (43 cases), Azerbaijan Sharghi province (Azeri Turkish) in the northwest (24 cases) and Bushehr province (Bushehri) in the south (35 cases). 548 normal hearing controls were recruited from Charmahal va Bakhtiari province (200 cases), Fars province (100 cases), Azerbaijan Sharghi province (100 cases) and Bushehr province (148 cases).

A well-designed questionnaire filled out for each family together with clinical evaluations helped exclude cases with syn- 
dromic forms, unilateral or mixed HI as well as those with a history of infection during pregnancy and bacterial meningitis. Informed consent was taken from all the family members. The study was approved by the Institutional Review Boards of Shahrekord University of Medical Sciences and Tarbiat Modares University.

\subsection{DNA extraction and Mutation screening}

Five $\mathrm{ml}$ of whole blood was collected in 0.5 M EDTA containing tubes. Genomic DNA was extracted by a standard phenol chloroform method (Grimberg et al., 1989). DNA concentration and purity was measured by spectrophotometry (UNICO 2100, USA). At least, one patient from every pedigree was subjected to DNA sequencing using primers and conditions previously described (Tabatabaiefar et al., 2011).

We sequenced GJB2 gene in all NSHI probands as described previously (Hashemzadeh Chaleshtori et al., 2007). No mutation in GJB2 gene found in probands. Then, Screening of A1555G mutation was performed by PCR-RFLP strategy. We carried out PCR amplification of a $566 \mathrm{bp}$ fragment of the mitochondrial MT-RNR1 gene harboring the mutation site using the forward primer 5'CAC AAA ATA GAC TAC GAA AGT GGC-3' and Restriction site creator reverse primer 5'- ACT TAC CAT GTT ACG ACT GG-3' with the purpose of creating a restriction site for HaeIII to screen the A1555G mutation. Digestion with the restriction endonuclease HaeIII was followed. The restriction fragment products were visualized on a $12 \%$ polyacrylamide gel by silver staining. In the wild type allele, digestion products revealed two fragments of $455 \mathrm{bp}$ and $111 \mathrm{bp}$. The mutation creates an additional restriction site for HaeIII generating three fragments in the PCR product (455 bp, $91 \mathrm{bp}$ and $20 \mathrm{bp}$ ).

\section{Results}

The A1555G mutation was detected in two out of the 152 NSHI probands (1.3\%) and in none of the 548 control individuals with a normal hearing (Fig.1A.). Both probands harboring the A1555G mutation were in homoplasmic status. This result was confirmed by direct sequencing of the corresponding PCR product (Fig.1B.). Proband 1, a 20 year old man, was from Azerbaijan Sharghi province (Azeri Turkish). His HI was congenital, profound, bilateral and sensorineural. The GJB2 gene was sequenced by direct sequencing method in $152 \mathrm{NSHI}$ probands but no mutation was found. His verbal communication skill was rather poor. After administration of hearing aid, an improvement in oral communication was shown to occur in the follow-up examination.

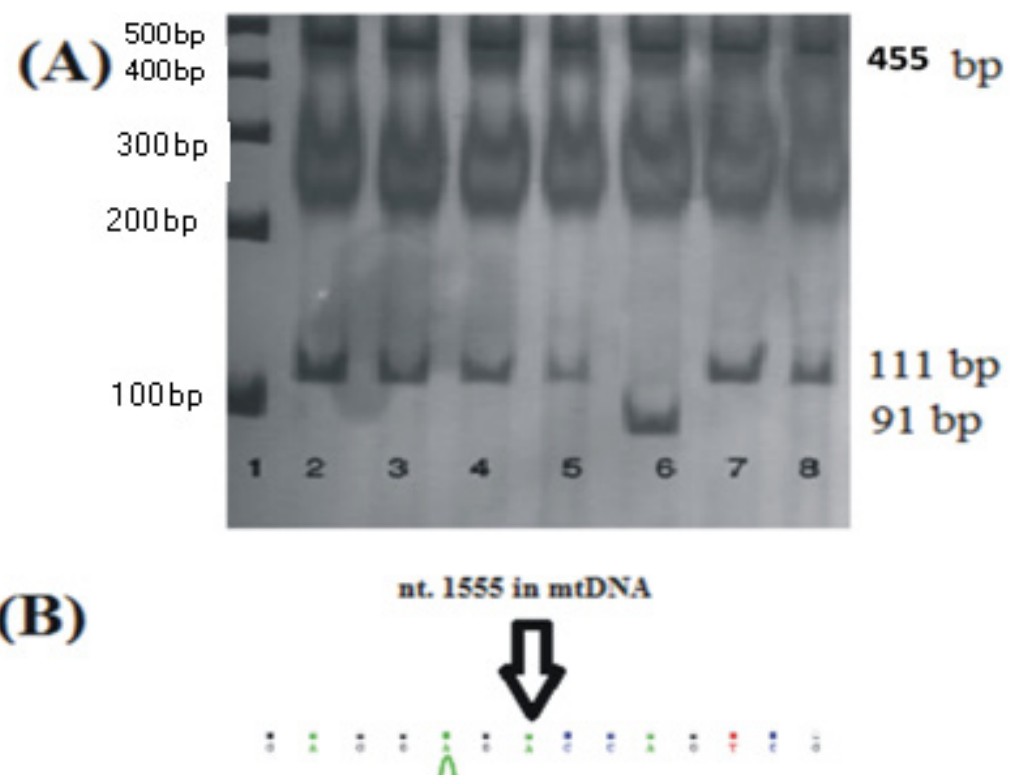

Fig.1. (A): PCR-RFLP analysis of Iranian patients with HI: a 566 bp PCR fragment is digested with Haell. The wild-type mtDNA is cleaved into two fragments, 455bp, and $111 \mathrm{bp}$ in length (panels 2-5, 7 and 8). PCR product containing the $A 1555 \mathrm{G}$ mutation is cleaved in to three fragments, 455, 91 and 20 bp in length (panel 6). DNA ladder (SM0241) (panel 1) (B): Sequence chromatograms from a normal hearing individual (top) and affected proband with the A1555G mutation in the mitochondrial 125 rRNA gene (down) 
His mother and two sisters were positive for the $\mathrm{A} 1555 \mathrm{G}$ mutation but only the younger sister, 13 years of age, was hearing impaired at higher frequencies. The expressivity of $\mathrm{HI}$ among family members carrying the mutation A1555G was highly variable, ranging from profound, moderate to completely normal hearing. Incomplete penetrance of the A1555G in this family was quite noticeable.

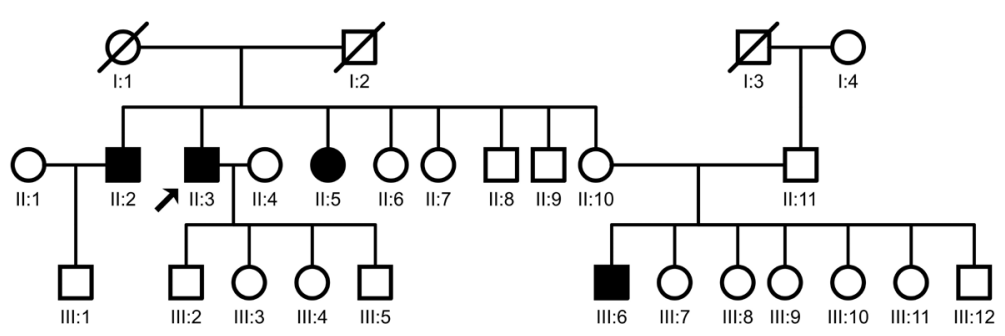
Fig.2. Pedigree of the proband 2 family segregating for the A1555G mutation in the mitochondrial 125 rRNA gene

Proband 2 (II: 3, Fig.2.), a 54 year old male from Bushehr province (Bushehri), had severe, bilateral and sensorineural deafness and with no GJB2 mutation. The onset of $\mathrm{HI}$ was at 7 years of age at higher frequencies. The hearing impairment phenotype got worse with age at all frequencies. No information was available regarding a possible exposure to aminoglycoside antibiotics. He had two male and two female offspring that were normal hearing (Fig.2.). He had four female and three male siblings (Fig.2.). The A $1555 \mathrm{G}$ mutation was verified in all of the siblings of the proband. However, the sign of HI was only present in one brother (II:2) and one sister (II:5) aged 71 and 53 years, respectively, who were affected with severe sensorineural HI with childhood onset. His healthy youngest sister (II: 10) had 7 children one of whom (III:6) was affected with congenital severe HI (Fig.2.). The A1555G mutation was detected in all of her offspring providing further evidence for the incomplete penetrance.

Overall, two probands carrying homoplasmic A1555G were found in this study. The scrutiny of all family members of both probands confirmed the presence of the mutation $\mathrm{A} 1555 \mathrm{G}$ and its strict inheritance in a maternal pattern. The frequency of the mutation A1555G in Azeri Turkish, Bushehri, Lure and Fars subpopulations were 4.16\% (1/24), 2.86\% (1/35), 0.0\% (0/50) and 0.0\% (0/43), respectively.

\section{Discussion}

Mutations in the mitochondrial DNA, especially $12 \mathrm{~S}$ rRNA and tRNA ${ }^{\text {ser }(\mathrm{UCN})}$, usually cause progressive non-syndromic hearing impairment (NSHI) (Kokotas et al., 2007). NSHI-linked mutations often exist in homoplasmy or at high levels of heteroplasmy implying high threshold levels for pathogenicity of the mtDNA mutations (Finsterer \& Fellinger, 2005). The mitochondrial DNA mutations have highly variable phenotypic expression indicating the contribution of three major modulators involving nuclear modifier genes, environmental factors and mitochondrial haplotypes (Guan, 2004).

The mutation A1555G is the most common 12S rRNA mutation associated with various phenotypes from profound $\mathrm{HI}$ to completely normal hearing. This mutation was first illustrated in a large Arab-Israeli family (Prezant et al., 1993). So far, no report exists regarding the involvement of the mtDNA mutations in pathogenesis of deafness in Iran. Our study shows that the average frequency of the $\mathrm{A} 1555 \mathrm{G}$ mutation was $1.3 \%$ in the Iranian deaf population. Iran is strategically located in the tri-continental corridor uniting 3 continents including Asia, Africa and Europe. This variable frequency could be due to ascertainment bias or as a true different prevalence in subpopulations of different ethnic origin in Iran. Different ethnic groups belonging to distinct religions and speaking in different languages, such as Fars, Azeri Turk, Gilaki, Kurd, Arab, Turkaman, Mazandarani, Lur, Baluchi, Zaboli, Bushehri and Mashhadi, live in Iran generating a potentially diverse genetic reservoir. The role and mutation frequency in the known genes linked to HI are highly variable in various ethnic groups of Iran (Chalehtori et al., 2007; Mahdieh et al., 2010; Tabatabaiefar et al., 2011). Comprehensive studies in different ethnic groups residing in discrete regions of the Iran showed high frequency rates of GJB2 mutations in autosomal recessive NSHI families in Gilan (34\%) in the north and Azarbaijan sharghi (27.5\%) in the northwest and of the country. However, very lower frequencies were found in Hormozgan (4.3\%) in the south and Sistan va Baluchistan (3.6\%) in the southeast of Iran (Hashemzadeh et al., 2007; Najmbadi et al., 2005). This situation can be inferred, more or less precisely, for other genes causing NSHI as well as other diseases. In agreement with the hypothesis, mutation A1555G was present with variable frequencies among various ethnic groups ranging from 4.16\% in Azeri Turkish, 2.86\% in Bushehri, to 0.0\% in Lur and Fars populations.

In families of both probands harboring the A1555G mutation, 6 of 19 carriers were affected with pre-lingual or progressive sensorineural HI. Severity and onset of age in carriers were variable from completely normal hearing to profound deafness with con- 
genital or late onset indicating the phenotypic heterogeneity caused by the $\mathrm{A} 1555 \mathrm{G}$ mutation. As no mutation was found in the GJB2 gene, further research is needed to identify the modifier genes or factors. Higher prevalence of this mutation among Azeri Turkish and Bushehri populations might also be due to a founder effect. The frequency of A1555G mutation has been determined in various populations of different ethnic origin (Table 1).

Table 1. Frequency of $A 1555 \mathrm{G}$ mutation in different populations worldwide

\begin{tabular}{||l||l|l|l||}
\hline \multicolumn{1}{|c|}{ Continent } & \multicolumn{1}{|c|}{ Population } & $\begin{array}{c}\text { Frequency of } \\
\text { A1555G }\end{array}$ & \multicolumn{1}{|c|}{ Reference } \\
\hline \hline Europe & Belgium & $0.3 \%$ & Konings et al., 2008 \\
\hline & Greece & $0.42 \%$ & Kokotas et al., 2009 \\
\hline & Germany & $0.7 \%$ & Kupka et al., 2002 \\
\hline & Hungary & $1.8 \%$ & Kupka et al., 2002 \\
\hline & Turkey & $1.8 \%$ & Tekin et al., 2003 \\
\hline & Poland & $2.4 \%$ & Kupka et al., 2002 \\
\hline & Italian & $15.57 \%$ & Jacobs et al., 2005 \\
\hline America & Spanish & $27.14 \%$ & Estivill et al., 1998 \\
\hline & USA & $0.6 \%$ & Li et al., 2004a \\
\hline & USA & $0.0 \%$ & Samanich et al., 2007 \\
\hline Africa & Brazilian & $2 \%$ & Abreu et al., 2006 \\
\hline & Tunisian & $1 \%$ & Mkaouar et al., 2008 \\
\hline Asia & Morocco & $3.6 \%$ & Nahili et al., 2010 \\
\hline & Korea & $0.9 \%$ & Bae et al., 2008 \\
\hline & Chinese & $2.9 \%$ & Li et al., 2005 \\
\hline & Japanese & $3.45 \%$ & Abe et al., 1998 \\
\hline & Japanese & $7.7 \%$ & Usami et al., 2000 \\
\hline & Indonesia & $5.3 \%$ & Malik et al., 2003 \\
\hline & Iranian & $1.3 \%$ & This study \\
\hline & & &
\end{tabular}

By and large, mutation frequency of $\mathrm{A} 1555 \mathrm{G}$ in different ethnic groups of Iran is in the range reported for most of other populations. Furthermore, the findings of the present study confirm those of several other studies on the genetic bases of HI in Iran suggesting highly variable mutation frequencies among different ethnic groups. Ethnicity of the proband could be a significant factor in genetic counseling programs in such countries as Iran with the heterogeneous population. In general, it might be worth screening for mitochondrial DNA mutations, especially A1555G, in people from certain populations with higher frequencies of the mutation before starting treatment by aminoglycoside antibiotics as to prevent from HI.

\section{Acknowledgements}

This research was funded by Shahrekord University of Medical Sciences and Tarbiat Modares University, Iran. We would like to sincerely thank the families for their cooperation in the process of this research. We are grateful to the staff of Cellular and Molecular Research Center of Shahrekord University of Medical Sciences for assisting in sample collection. The authors hereby declare that there is no conflict of interests. 


\section{Reference}

1 Abe S, Usami S, Shinkawa H, Weston MD, Overbeck LD, Hoover DM, Kenyon JB, Horai S and Kimberling WJ, (1998) "Phylogenetic analysis of mitochondrial DNA in Japanese pedigrees of sensorineural hearing loss associated with the A1555G mutation." Eur. J. Hum. Genet. 6(6), 563-569.

2- Abreu-Silva RS, Lezirovitz K, Braga MC, Spinelli M, Pirana S, Della-Rosa VA, Otto PA and Mingroni-Netto RC, (2006) "Prevalence of the A1555G (12S rRNA) and tRNASer (UCN) mitochondrial mutations in hearing-impaired Brazilian patients." Braz. J. Med. Biol. Res. 39(2), 219-226.

3• Bae JW, Lee KY, Choi SY, Lee SH, Park HJ and Kim UK, (2008) "Molecular analysis of mitochondrial gene mutations in Korean patients with nonsyndromic hearing loss." Int. J. Mol. Med. 22(2), 175-180.

4- Chaleshtori MH, Farrokhi E, Shahrani M, Kheiri S, Dolati M, Rad LH, Pour-Jafari H, Samani KG, Chaleshtori KS and Crosby AH, (2007) "High carrier frequency of the GJB2 mutation (35delG) in the north of Iran." Intl. J. Pediatr Otorhinolaryngol. 71(6), 863-867.

5• Estivill X, Govea N, Barcelo E, Badenas C, Romero E, Moral L, Scozzri R, D’Urbano L, Zeviani M and Torroni A, (1998) "Familial progressive sensorineural deafness is mainly due to the mtDNA A1555G mutation and is enhanced by treatment of aminoglycosides." Am. J. Hum. Genet. 62(1), 27-35.

6• Finsterer J and Fellinger J, (2005) "Nuclear and mitochondrial genes mutated in nonsyndromic impaired hearing." Int. J. Pediatr Otorhinolaryngol. 69(5), 621-647.

7• Grimberg J, Nawoschik S, Belluscio L, McKee R, Turck A and Eisenberg A 1989 “A simple and efficient non-organic procedure for the isolation of genomic DNA from blood." Nucleic Acids Res. 17(20), 83-90.

8- Guan MX 2004 "Molecular pathogenetic mechanism of maternally inherited deafness." Ann. N. Y. Acad. Sci. 1011, 259-271.

9• Hashemzadeh Chaleshtori M, Farhud DD and Patton MA, (2007) "Familial and sporadic GJB2-related deafness in Iran: Review of gene mutations." Iran. J. Publ. Health. 36, 1-14.

10• Jacobs HT, Hutchin TP, Kappi T, Gillies G, Minkkinen K, Walker J, Thompson K, Rovio AT, Carella M, Melchionda S, Zelante L, Gasparini P, Pyykko I, Shah ZH, Zeviani M and Mueller RF (2005), "Mitochondrial DNA mutations in Patients with postlingual, nonsyndromic hearing impairment.” Eur. J. Hum. Genet. 13(1), 26-33.

11 Kokotas H, Grigoriadou M, Korres GS, Ferekidou E, Papadopoulou E, Neou P, Giannoulia-Karantana A, Kandiloros D, Korres $\mathrm{S}$ and Petersen MB, (2009) "The A1555G mitochondrial DNA mutation in Greek patients with non-syndromic, sensorineural hearing loss.” Biochem. Biophys. Res. Commun. 390(3), 755-757.

12• Kokotas H, Petersen MB and Willems PJ, (2007) "Mitochondrial deafness." Clin. Genet. 71(5), 379-391.

13. Konings A, Van Camp G, Goethals A, Van Eyken E, Vandevelde A, Ben Azza J, Peeters N, Wuyts W, Smeets H and Van Laer L, (2008) "Mutation analysis of mitochondrial DNA 12SrRNA and tRNASer(UCN) genes." in Non-syndromic hearing loss patients. Mitochondrion. 8(5-6), 377-382.

14- Kupka S, Toth T, Wrobel M, Zeissler U, Szyfter W, Szyfter K, Niedzielska G, Bal J, Zenner HP, Sziklai I, Blin N and Pfister M 2002 'Mutation A1555G in the 12S rRNA gene and its epidemiological importance in German, Hungarian, and Polish patients." Hum. Mutat. 19(3), 308-309.

15• Li R, Greinwald JH, Jr, Yang L, Choo DI, Wenstrup RJ and Guan MX, (2004a) "Molecular analysis of the mitochondrial 12S rRNA and tRNASer(UCN) genes in Paediatric subjects with non-syndromic hearing loss.” J. Med. Genet. 41(8), 615-620.

16• Li R, Xing G, Yan M, Cao X, Liu XZ, Bu X and Guan MX, (2004b) "Cosegregation of C-insertion at position 961 with the A1555G mutation of the mitochondrial $12 \mathrm{~S}$ rRNA gene in a large Chinese family with maternally inherited hearing loss." Am. J. Med. Genet. A. 124A(2), 113-117.

17• Li Z, Li R, Chen J, Liao Z, Zhu Y, Qian Y, Xiong S, Heman-Ackah S, Wu J, Choo DI and Guan MX, (2005) "Mutational analysis of the mitochondrial $12 \mathrm{~S}$ rRNA gene in Chinese pediatric subjects with aminoglycoside-induced and non-syndromic hearing loss." Hum. Genet. 117(1), 9-15.

18- Mahdieh N, Rabbani B, Wiley S, Akbari MT and Zeinali S, (2010) "Genetic causes of nonsyndromic hearing loss in Iran in comparison with other populations." J. Hum. Genet. 55(10), 639-648. 
19• Malik SG, Pieter N, Sudoyo H, Kadir A and Marzuki S, (2003) "Prevalence of the mitochondrial DNA A1555G mutation in sensorineural deafness patients in island Southeast Asia." J. Hum. Genet. 48(9), 480-483.

20• Marazita ML, Ploughman LM, Rawlings B, Remington E, Arnos KS and Nance WE, (1993) "Genetic epidemiological studies of early-onset deafness in The U.S. school-age population.” Am. J. Med. Genet. 46(5), 486-491.

21 Mkaouar-Rebai E, Tlili A, Masmoudi S, Charfeddine I and Fakhfakh F, (2008) "New polymorphic mtDNA restriction site in the 12S rRNA gene detected in Tunisian patients with non-syndromic hearing loss." Biochem. Biophys. Res. Commun. 369(3), 849-852.

22• Morton CC and Nance WE, (2006) "Newborn hearing screening--a silent revolution.” N. Engl. J. Med. 354(20), 2151-2164.

23- Nahili H, Charif M, Boulouiz R, Bounaceur S, Benrahma H, Abidi O, Chafik A, Rouba H, Kandil M and Barakat A, (2010) "Prevalence of the mitochondrial A $1555 \mathrm{G}$ mutation in Moroccan patients with non-syndromic hearing loss." Intl. J. Pediatr. Otorhinolaryngol. 74(9), 1071-1074.

24- Najmabadi H, Nishimura C, Kahrizi K, Riazalhosseini Y, Malekpour M, Daneshi A, Farhadi M, Mohseni M, Mahdieh N, Ebrahimi A, Bazazzadegan N, Naghavi A, Avenarius M, Arzhangi S and Smith RJ, (2005) "GJB2 mutations: passage through Iran." Am. J. Med. Genet. A 133A(2), 132-7.

25• Prezant TR, Agapian JV, Bohlman MC, Bu X, Oztas S, Qiu WQ, Arnos KS, Cortopassi GA, Jaber L and Rotter JI, (1993) “Mitochondrial ribosomal RNA mutation associated with both antibiotic-induced and non-syndromic deafness." Nat. Genet. 4(3), $289-94$.

26• Samanich J, Lowes C, Burk R, Shanske S, Lu J, Shanske A and Morrow BE, (2007) "Mutations in GJB2, GJB6, and mitochondrial DNA are rare in African American and Caribbean Hispanic individuals with hearing impairment." Am. J. Med. Genet. A. $143 \mathrm{~A}(8), 830-838$.

27- Tabatabaiefar MA, Alasti F, Montazer Zohour M, Shariati L, Farrokhi E, Farhud DD, Camp GV, Noori-Daloii MR and Chaleshtori MH, (2011) "Genetic linkage Analysis of 15 DFNB Loci in A group of Iranian families with Autosomal recessive hearing loss." Iran. J. Pub. Health. 40(2), 34-48.

28- Tekin M, Duman T, Bogoclu G, Incesulu A, Comak E, Fitoz S, Yilmaz E, Ilhan I and Akar N, (2003) "Frequency of mtDNA A1555G and A7445G mutations among children with prelingual deafness in Turkey." Eur. J. Pediatr. 162(3), 154-158.

29• Usami S, Abe S, Akita J, Namba A, Shinkawa H, Ishii M, Iwasaki S, Hoshino T, Ito J, Doi K, Kubo T, Nakagawa T, Komiyama S, Tono T and Komune S, (2000) "Prevalence of mitochondrial gene mutations among hearing impaired patients." J. Med. Genet. $37(1), 38-40$. 